\title{
ICARE software for calculation of dose coefficients and retained/excreted fractions of intake
}

\author{
Eric Blanchardon ${ }^{1, *}$, Estelle Davesne ${ }^{1}$, Sandra Bohand $^{2}$, and Pierre Laroche ${ }^{2}$ \\ ${ }^{1}$ IRSN, Fontenay-aux-Roses, France \\ ${ }^{2}$ ORANO, Paris, France
}

The assessment of internal exposure for workers is usually based on ambient activity measured at the workplace or individual activity from bioassay interpreted with dose coefficients and time-dependent retained and excreted fractions of intake established by the International Commission on Radiological Protection (ICRP) from reference biokinetic and dosimetric models.

To gain flexibility in the implemented models and enable consideration of non-standard situations of exposure such as wound contamination, clinical trials of radiopharmaceuticals, exposure to radon decay products with specific aerosol parameters or intake followed by decorporation treatment, a new software module, called "Internal dose CAlculation for Radionuclide Exposure (ICARE)", was developed for expertise and research. It provides the dose coefficients and retained/excreted fractions used by OPSCI software [1] (IRSNORANO) which performs occupational dose calculation from bioassay measurement, evaluates the associated uncertainty and supports design of monitoring programs of internal exposure.

ICARE will be presented as software developed with the Interactive Data Language (IDL, Harris) to implement biokinetic models of the ICRP 60 [2] series of publications by the method described by Leggett et al. [3]. It provides retained fractions of intake in body regions, daily urinary and fecal excretions after occupational exposure by inhalation, ingestion or wound [4]. S coefficient values are calculated from emission spectra of ICRP [5] convoluted with specific absorbed fractions published by Cristy and Eckerman [6] for photons and by ICRP $[7,8]$ for electrons and alpha particles. S coefficients are combined with numbers of nuclear transformations to provide absorbed, equivalent and effective doses per unit intake.

For validation, calculation results were extensively compared with ICRP equivalent and effective dose coefficients [9] and with bioassay quantities predicted by DCAL [10] and IMBA [11] software. Examples for specific exposure situations will be presented. Further development is planned to include age-dependent models and revised ICRP models implemented in the Occupational Intakes of Radionuclides series of publications [12] with the objective of contributing to the quality assurance of the on-going update of ICRP dose coefficients for internal exposure.

\section{References}

[1] E. Davesne, M. Vincent, E. Blanchardon, M. Rennesson, P. Laroche, D. Franck. IAEA(ed.) Vienna (2014) Available at: http://www-ns.iaea.org/tech-areas/communicationnetworks/orpnet/documents/CN223_Book\%20of\%20contributed\%20papers.pdf

[2] ICRP Publication 60. Ann. ICRP 21 (1-3) (1991)

* Corresponding author: eric.blanchardon@irsn.fr 
[3] R.W. Leggett, K.F. Eckerman, L.R. Williams, Health Phys. 64, 260 (1993)

[4] National Council on Radiation Protection and Measurements. Bethesda, MD: NCRP; Report No. 156 (2006)

[5] ICRP Publication 38. Ann. ICRP 11-13 (1983)

[6] M. Cristy, K.F. Eckerman. ORNL/TM-8381/V1-7, Oak Ridge National Laboratory, Oak Ridge, TN (1987)

[7] ICRP Publication 30 (Part 1). Ann. ICRP 2 (3-4) (1979)

[8] ICRP Publication 66. Ann. ICRP 24 (1-3) (1994)

[9] ICRP. Available at http://www.icrp.org/docs/ICRPDOSE_setup.exe.

[10] K.F. Eckerman, R.W. Leggett, M. Cristy, C.B. Nelson, J.C. Ryman, A.L. Sjoreen, R.C. Ward. Oak Ridge, TN: Oak Ridge National Laboratory; Report ORNL/TM-2001/190 (2006)

[11] A. Birchall, M. Puncher, J.W. Marsh, K. Davis, M.R. Bailey, N.S. Jarvis, A.D. Peach, M.-D. Dorrian, A.C. James, Radiat. Prot. Dosim. 125, 194 (2007)

[12] ICRP Publication 130. Ann. ICRP 44(2) (2015) 